\title{
Elena-Brânduşa Steiciuc, L'être hybride confronté à ses origines dans trois romans de Malika Mokeddem
}

\section{Ilaria Vitali}

\section{(2) OpenEdition}

\section{Journals}

\section{Edizione digitale}

URL: http://journals.openedition.org/studifrancesi/7737

DOI: $10.4000 /$ studifrancesi.7737

ISSN: 2427-5856

\section{Editore}

Rosenberg \& Sellier

\section{Edizione cartacea}

Data di pubblicazione: 1 décembre 2009

Paginazione: 675-676

ISSN: 0039-2944

\section{Notizia bibliografica digitale}

Ilaria Vitali, «Elena-Brânduşa Steiciuc, L'être hybride confronté à ses origines dans trois romans de Malika Mokeddem», Studi Francesi [Online], 159 (LIII | III) | 2009, online dal 30 novembre 2015, consultato il 09 janvier 2021. URL: http://journals.openedition.org/studifrancesi/7737 ; DOI: https://doi.org/10.4000/ studifrancesi.7737

Questo documento è stato generato automaticamente il 9 janvier 2021.

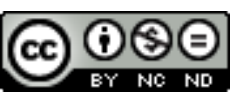

Studi Francesi è distribuita con Licenza Creative Commons Attribuzione - Non commerciale - Non opere derivate 4.0 Internazionale. 


\title{
Elena-Brânduşa Steiciuc, L'être hybride confronté à ses origines dans trois romans de Malika Mokeddem
}

\author{
Ilaria Vitali
}

\section{NOTIZIA}

ELENA-BRÂNDUŞA STEICIUC, L'être hybride confronté à ses origines dans trois romans de Malika Mokeddem, in Id., La francophonie au féminin, Iaşi, Éditions Universitas XxI, 2007, pp. 126-139.

1 È riservato a Malika Mokeddem, scrittrice algerina da anni in esilio in Francia, l'ultimo capitolo di questo prezioso saggio che Elena-Brându sa Steiciuc dedica ad alcune delle figure più significative della "francophonie au féminin». Dopo dieci capitoli consacrati ad altrettante autrici francofone, provenienti in particolare dall'Europa orientale, Steiciuc si concentra su una delle voci più interessanti del panorama maghrebino. L'epigrafe del saggio, tratta dal romanzo L'Interdite di Mokeddem (Grasset, 1993), pone subito l'attenzione sul tema centrale che sarà affrontato dalla studiosa, il concetto d'ibridità: «Je suis plutôt dans l'entre-deux, sur une ligne de fracture, dans toutes les ruptures. [...] Dans un entre-deux qui cherche ses jonctions entre le Sud et le Nord, ses repères dans deux cultures» (p. 126).

Nata nel 1949 a Kenadsa, nel sud algerino, Mokeddem vive in Francia dal 1979 e s'inscrive nella linea di quelle scrittrici espatriate che hanno saputo sfruttare l'esperienza dell'esilio per acuire il loro sguardo critico sul paese d'origine così come su quello d'accoglienza. Come spiega Steiciuc, in un continuo movimento di va-et-vient tra la cultura araba maghrebina e quella francese, Mokeddem affronta nella sua opera complessi temi che ruotano attorno alla questione dell'être hybride: la speranza e il disincanto di chi lascia il paese natale, il nomadismo, la memoria e l'oblio. Attraverso l'analisi di tre romanzi, stilisticamente molto diversi - Les hommes qui marchent (1990), 
Le Siècle des sauterelles (1992) e L'Interdite (1993) - Steiciuc mostra le molteplici sfaccettature del concetto d'ibridità. Ne emerge così non soltanto l'evoluzione dello stile dell'autrice, ma soprattutto quella della sua poetica e della sua visione in fieri di quel «luogo» di frontiera, multiforme ed instabile, che è l'entre-deux. 